\title{
Anticorrosion Coating of Carbon Nanotube/Polytetrafluoroethylene Composite Film on the Stainless Steel Bipolar Plate for Proton Exchange Membrane Fuel Cells
}

\author{
Yoshiyuki Show, Toshimitsu Nakashima, and Yuta Fukami \\ Department of Electrical and Electronic Engineering, School of Engineering, Tokai University, 4-1-1 Kitakaname, \\ Hiratsuka, Kanagawa 259-1292, Japan \\ Correspondence should be addressed to Yoshiyuki Show; show@tokai-u.jp
}

Received 6 March 2013; Accepted 14 June 2013

Academic Editor: Renzhi Ma

Copyright (c) 2013 Yoshiyuki Show et al. This is an open access article distributed under the Creative Commons Attribution License, which permits unrestricted use, distribution, and reproduction in any medium, provided the original work is properly cited.

Composite film of carbon nanotube (CNT) and polytetrafluoroethylene (PTFE) was formed from dispersion fluids of CNT and PTFE. The composite film showed high electrical conductivity in the range of $0.1-13 \mathrm{~S} / \mathrm{cm}$ and hydrophobic nature. This composite film was applied to stainless steel (SS) bipolar plates of the proton exchange membrane fuel cell (PEMFC) as anticorrosion film. This coating decreased the contact resistance between the surface of the bipolar plate and the membrane electrode assembly (MEA) of the PEMFC. The output power of the fuel cell is increased by 1.6 times because the decrease in the contact resistance decreases the series resistance of the PEMFC. Moreover, the coating of this composite film protects the bipolar plate from the surface corrosion.

\section{Introduction}

Carbon nanotubes (CNTs) exhibit remarkable thermal, electrical, and mechanical properties which are associated with their unique structure, high aspect ratio, and quantum size effects. Because of these properties, the CNT has been widely studied for applications such as heatsink [1], microelectronic interconnects [2], and structural composites [3].

The CNT is also a promising filler in resins. The composite film of CNT and polytetrafluoroethylene (PTFE) was studied as tribology [4,5] and anticorrosion [6] coatings. One of the applications of the CNT/PTFE composite film is anticorrosion coating for the bipolar plates of the proton exchange membrane fuel cells (PEMFCs). The anticorrosion film for the bipolar plate is required to be electrochemically stable at acid and humid environment, because the inside of the fuel cell is 3.7-4.1 in pH [7]. Moreover, the film needs electrical conductivity, because the bipolar plates work as the electrodes in the fuel cell [8].

The CNT/PTFE composite film shows high electrical conductivity, because the CNTs with high electrical conduction in the film, while the PTFE is electrically insulating. Moreover, both CNT and PTFE are chemically stable materials. These properties of the CNT/PTFE composite film satisfy the requirements as the anticorrosion film for the bipolar plate.

In this study, the carbon nanotube and polytetrafluoroethylene (CNT/PTFE) composite film $[9,10]$ was formed from dispersion fluids of CNT and PTFE. The properties of the composite film at various CNT concentrations were studied. Moreover, the composite film was coated on stainless steel (SS) bipolar plates of the PEMFC as anticorrosion film. The influence of composite film coating on the characteristic of the PEMFC was investigated.

\section{Experiments}

2.1. Formation of CNT/PTFE Composite Film. CNT/PTFE composite film was formed from CNT and PTFE dispersion fluids. The CNT dispersion fluid was made from multiwalled type CNTs with $10 \mathrm{~nm}$ diameter and 30 or $100 \mu \mathrm{m}$ length. Carboxymethylcellulose (CMC) was added to the water in order to disperse the CNT. This CNT dispersion was made by 


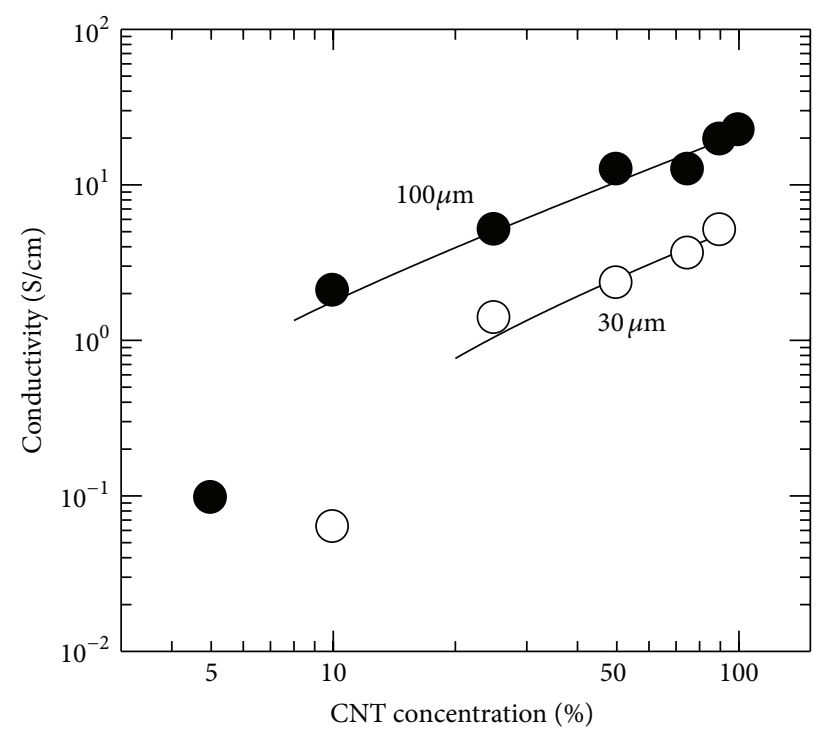

(a)

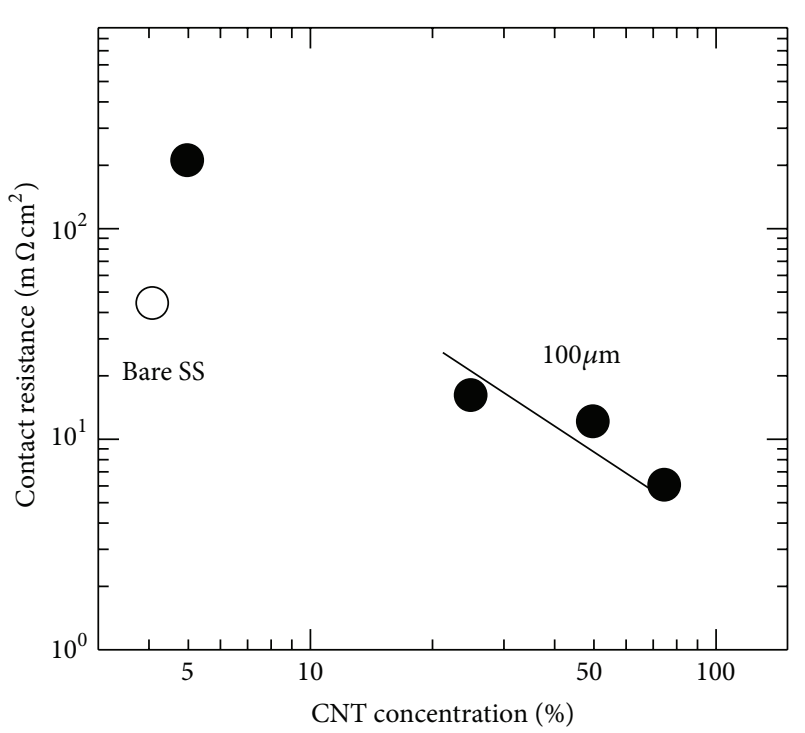

(b)

Figure 1: (a) The conductivity of the CNT/PTFE composite film coated on glass substrate at various CNT concentrations. The CNTs with the lengths of 30 and $100 \mu \mathrm{m}$ were used. (b) The contact resistance between the carbon paper and the bipolar plate coated at various CNT concentrations. The CNT with the length of $100 \mu \mathrm{m}$ was used.

means of the technique reported in [11]. The CNT concentration in the dispersion fluid was 3 wt.\%. The CNTs were well dispersed in the water although the CNT concentration was of a high value. It has been reported that CMC was a suitable dispersant for CNT, because it reduces hydrophobic interaction of CNTs [11-13].

Water-based commercial PTFE dispersion was used in this study. The PTFE particles in the water were $0.20-0.40 \mu \mathrm{m}$ in diameter. The PTFE concentration was $60 \mathrm{wt} . \%$. The separate $\mathrm{CNT}$ and PTFE dispersion fluids were mixed and stirred by ultrasonic agitation. The CNT concentration in this mixed fluid was varied from 0 (pure-PTFE dispersion) to $100 \mathrm{wt} . \%$ (pure-CNT dispersion). The use of the CNT dispersion fluid achieves forming the mixed fluid of CNT and PTFE without sedimentation of the CNT [9, 10]. This mixed fluid was applied to glass substrate or stainless steel (304 SS) bipolar plate by doctor blade method. The thickness of the applied mixed fluid was varied from 80 to $180 \mu \mathrm{m}$ in order to keep the same thickness of the CNT/PTFE composite film. The sample was dried in $40^{\circ} \mathrm{C}$ atmosphere for $30 \mathrm{~min}$ and then was heated at $350^{\circ} \mathrm{C}$ for $10 \mathrm{~min}$. This process formed the CNT/PTFE composite film with the thickness of $5 \mu \mathrm{m}$.

2.2. Characterizations of the CNT/PTFE Composite Film. The CNT/PTFE composite film was characterized on the electrical conductivity, the contact resistance between the bipolar plate and carbon paper, the contact angle of water, and the polarization curve. The electrical conductivity of the film was measured on glass substrate by using the four point probe method. The contact resistance was measured by sandwiching carbon paper, which was used as gas diffusion layer of the MEA (membrane electrode assembly), with two pieces of the bipolar plates. The assembled pressure for the bipolar plates and carbon paper was 1.5 MPa. The current was flowed from one side of the bipolar plate to the other through the carbon paper. Polarization curve was measured in $1 \mathrm{M} \mathrm{H}_{2} \mathrm{SO}_{4}$ from corrosion potential to $1500 \mathrm{mV}$ versus $\mathrm{Ag} / \mathrm{AgCl}$ for stainless steel (SS) plate coated with the CNT/PTFE composite film. The $\mathrm{Ag} / \mathrm{AgCl}$ electrode was used as the reference. The scan rate of the potential voltage was $5 \mathrm{mV} / \mathrm{s}$.

2.3. Fabrication of Fuel Cell Using Stainless Steel Bipolar Plates Coated with the CNT/PTFE Composite Film. Proton exchange membrane fuel cells (PEMFCs) were assembled using bare stainless steel (304 SS) and the CNT/PTFE composite film coated SS bipolar plates. The concentration of the CNT in the coated film was varied from 5 to $75 \mathrm{wt} . \%$. The pure CNT film, which does not contain the PTFE as a binder, was not used in this study, because the film was detached from the bipolar plate when the film got wet in the fuel cell.

Nafion 117 was used as the polymer electrolyte of the PEMFC. The anode and the cathode electrodes contained platinum catalyst loading of $0.25 \mathrm{mg} / \mathrm{cm}^{2}$, which were supported on acetylene black powder. Carbon paper was used as gas diffusion layer. The membrane electrode assembly (MEA) was $4 \times 4 \mathrm{~cm}^{2}$ in the size. Humidified hydrogen and oxygen gases flowed into the anode and the cathode at 100 and $200 \mathrm{~mL} / \mathrm{min}$, respectively.

\section{Results and Discussion}

Figure 1(a) shows the electrical conductivity of the CNT/PTFE composite film coated on glass substrate at various CNT concentrations. In this study, the CNTs with the lengths of 100 and $30 \mu \mathrm{m}$ were used. No electrical conduction was observed for the pure PTFE film, since PTFE is a highly 


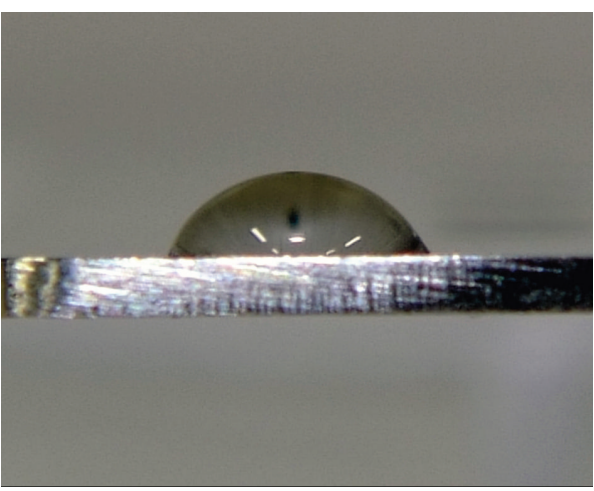

(a)

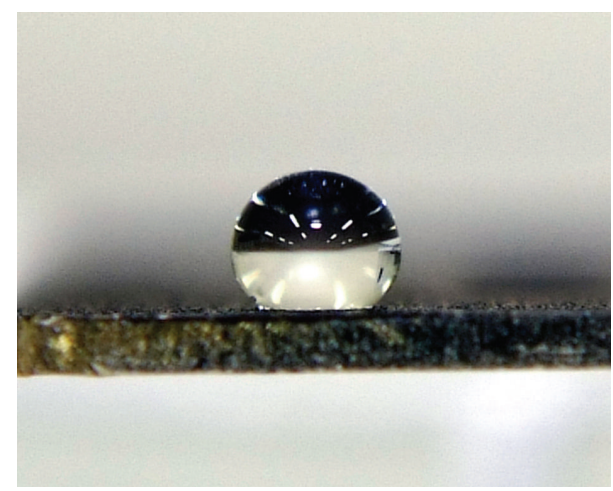

(b)

FIGURE 2: Photographs of water droplet on (a) the bare and (b) the CNT/PTFE composite film coated stainless steel (SS) plate.

insulating material. When the CNT with the length of $30 \mu \mathrm{m}$ was used, the composite film showed an electrical conductivity of $6 \times 10^{-2} \mathrm{~S} / \mathrm{cm}$ at the CNT concentration of $10 \mathrm{wt} . \%$. The electrical conductivity was drastically increased by over 10 times with an increase in the CNT concentration at 25 wt.\%. The electrical conductivity linearly increased up to $5 \mathrm{~S} / \mathrm{cm}$ with an increase in the CNT concentration between 25 and 75 wt.\%.

The transmission electron microscope (TEM) investigations indicate that the CNTs are successfully dispersed in the composite film [9]. The CNTs work as a conductive path throughout the composite film. However, a threedimensional conductive network of CNTs is needed to form highly conductive film. A CNT concentration of $10 \mathrm{wt} . \%$ is not high enough to form the three-dimensional conductive networks. Therefore, the composite film with $10 \mathrm{wt} . \%$ shows a relatively low conductivity of $6 \times 10^{-2} \mathrm{~S} / \mathrm{cm}$. On the other hand, the drastic increase in the conductivity at the CNT concentration of $25 \mathrm{wt} \%$ is because the three-dimensional conductive network is formed. This drastic increase in conductivity is called the percolation threshold [14].

The CNT/PTFE composite film containing the CNT with the length of $100 \mu \mathrm{m}$ has the low electrical conductivity of $0.1 \mathrm{~S} / \mathrm{cm}$ at the CNT concentration of $5 \mathrm{wt} . \%$. However, the longer CNT formed the three-dimensional conductive network at the lower concentration of $10 \mathrm{wt} . \%$. Moreover, the conductivity of the film linearly increased from 2 to high value of the $20 \mathrm{~S} / \mathrm{cm}$ with an increase in the CNT concentration from 25 to $75 \mathrm{wt}$.\%. Inclinations of the conductivity for the CNTs with the lengths of 30 and $100 \mu \mathrm{m}$ were almost the same, although the CNT with $100 \mu \mathrm{m}$ length was lower than that with $30 \mu \mathrm{m}$ length in the percolation threshold.

The films with a CNT concentration below $90 \mathrm{wt} . \%$ have flexibility, because the CNTs are bound by the PTFE. However, the film formed with exclusively the CNT is brittle. This film was easily broken into small particles of CNT by scratching it with tweezers. Moreover, the film came off by dipping it in water.

Figure 1(b) shows the contact resistance between the carbon paper and the bipolar plate coated at various CNT concentrations. The CNT with the length of $100 \mu \mathrm{m}$ was used for the constituent of the composite film. The bare (no the CNT/PTFE composite film coated) bipolar plate showed $23 \mathrm{~m} \Omega \mathrm{cm}^{2}$ in the contact resistance. When the CNT/PTFE composite film was coated on the SS bipolar plate at the CNT concentration of $5 \mathrm{wt} . \%$, the contact resistance was $200 \mathrm{~m} \Omega \mathrm{cm}^{2}$, which was higher than that of the bare stainless steel. The coating of CNT/PTFE composite film above the CNT concentration of $25 \mathrm{wt} \%$ decreased the contact resistance below $16 \mathrm{~m} \Omega / \mathrm{cm}^{2}$, which is lower than that of the bare stainless steel. The CNT/PTFE composite film above 25 wt. $\%$ is electrically conductive. Moreover, the CNTs physically contact to the bipolar plate and the carbon paper. These features of the composite film are considered to reduce the contact resistance. The bipolar plate material for transportation applications is required to be of interfacial resistance of $20 \mathrm{~m} \Omega \mathrm{cm}^{2}$ [8]. The SS bipolar plate coated with the CNT/PTFE composite film above $25 \mathrm{wt}$.\% satisfies the performance target of bipolar plate generally required as the contact resistance.

Figure 2 shows the photographs of water droplet on the bare and the CNT/PTFE film coated stainless steel (SS) plate. The water droplet on the bare stainless steel shows $60^{\circ}$ in the contact angle. The coating of the CNT/PTFE composite film increased the contact angle. Figure 3 shows the dependence of the CNT concentration on the contact angle. Pure PTFE film showed the contact angle of $110^{\circ}$, which is hydrophobic nature. The contact angle of the CNT/PTFE composite film increased to $145^{\circ}$ with an increase in the CNT concentration up to $25 \mathrm{wt}$. $\%$. The contact angle was almost of the same value above the concentration of $25 \mathrm{wt} . \%$. The CNT in the dispersion fluid is hydrophilic property because the surface of CNT is surrounded by the CMC as a dispersant. However, the thermal treatment at $350^{\circ} \mathrm{C}$ decomposes the $\mathrm{CMC}$ and changes the CNT surface from hydrophilic to hydrophobic property. The hydrophobic property of CNT increases the contact angle of the film. The coating of the CNT/PTFE composite film modifies the surface of stainless steel from hydrophilic to hydrophobic nature. The hydrophobic nature of the bipolar plate surface helps the water removals from the fuel cell and stabilizes the generation of electric power [15].

Figure 4 shows the dependence of the current on the output voltage and the electric power for the fuel cells assembled 


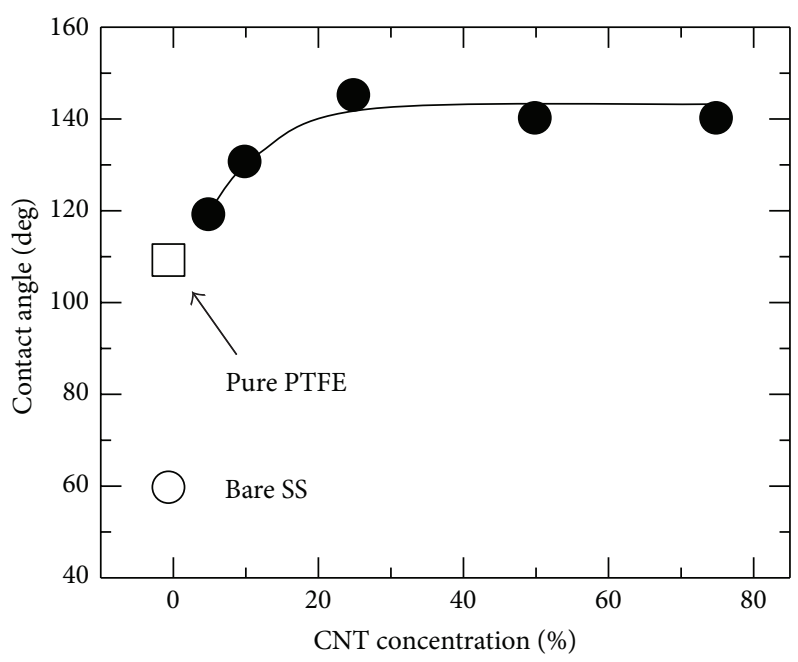

FIGURE 3: The dependence of the CNT concentration in the CNT/PTFE composite film on the contact angel of water droplet.

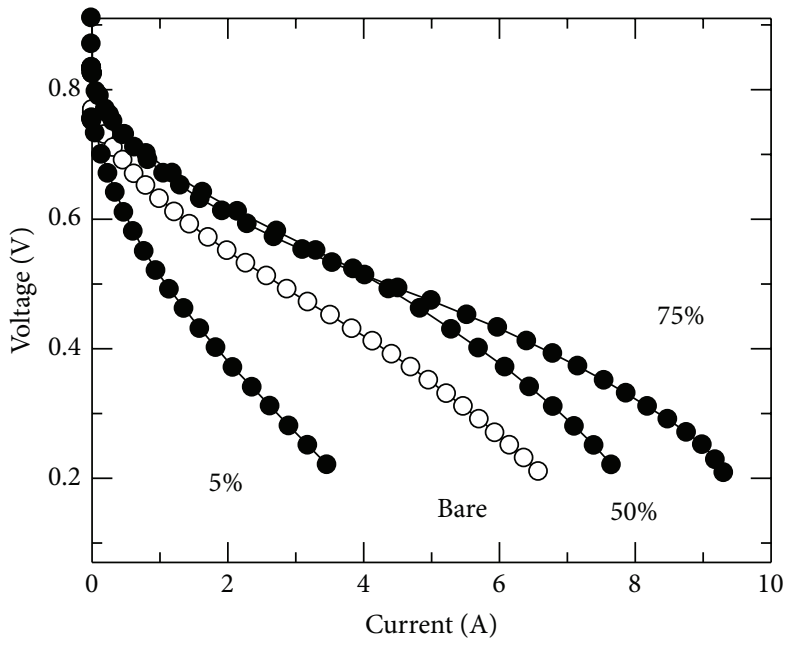

(a)

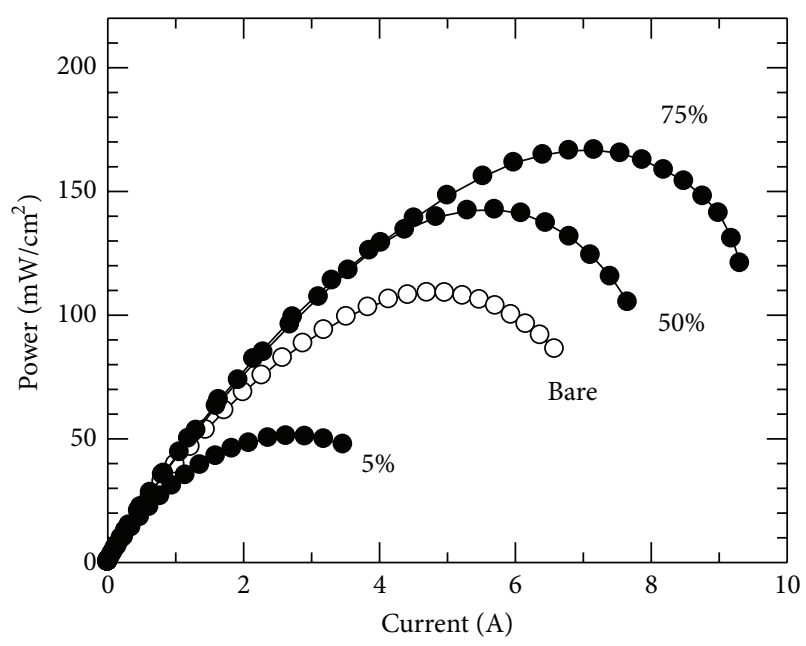

(b)

FIGURE 4: The dependence of the current on (a) the output voltage and (b) the electric power for the fuel cells assembled with the stainless steel (SS) bipolar plate coated with the CNT/PTFE composite film at various CNT concentrations.

with the bare SS bipolar plate or the SS bipolar plate coated with the CNT/PTFE composite film. All fuel cells showed an open voltage of $0.9 \mathrm{~V}$. No dependence on the bipolar plate was observed. The output voltage decreased with an increase in the current, because of the IR drop. When the CNT/PTFE composite film was coated on the SS bipolar plate at the low CNT concentration of $5 \mathrm{wt} . \%$, the output voltage was drastically decreased. The maximum output power for this fuel cell was $50 \mathrm{~mW} / \mathrm{cm}^{2}$, which is lower than that of the bare SS bipolar plate. On the other hand, the coating of the CNT/PTFE composite film with high CNT concentration prevented the IR drop in the output voltage. Therefore, these fuel cells showed the higher output power than that of the bare SS bipolar plate.

Figure 5 shows the cole-cole plot for the impedance measurements of the fuel cells assembled with the bare SS bipolar plates or those coated with the CNT/PTFE composite film at various CNT concentrations. Fuel cells showed a semicircular curve in the negative imaginary impedance $\left(-Z_{\text {img }}\right)$ region. The line shapes were almost the same for these fuel cells. However, the position of the semicircular curve on the real impedance $\left(Z_{\text {real }}\right)$ axis depended on the coating of the CNT/PTFE composite film. The fuel cell assembled with the bipolar plates coated with the CNT/PTFE composite film of 5 wt.\% held the higher position on the real impedance axis $\left(Z_{\text {real }}\right)$ than that of the bare SS bipolar plates. On the other hand, that of $75 \mathrm{wt} . \% \mathrm{CNT}$ concentration showed the coalcoal plot at lower position.

The equivalent circuit for the inner impedance of fuel cells is briefly assumed to consist of a capacitance $(C)$, a parallel resistance $\left(R_{p}\right)$ against the capacitance, and a series resistance $\left(R_{s}\right)$ against the parallel circuit of the capacitance as shown in Figure 6, since the cole-cole plots for the fuel cells were a semicircular curve. In the cole-cole plot, the lower and 


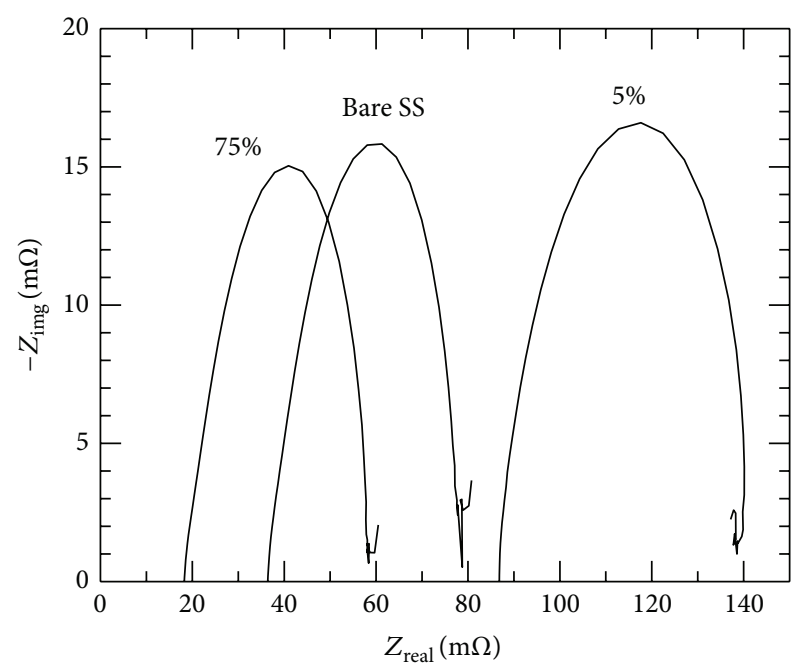

FIgURE 5: Cole-cole plot for the impedance measurements of the fuel cells assemble with the bare and the coated stainless steel (SS) bipolar plates.

the higher values of the real part at the imaginary part $\left(-Z_{\text {img }}\right)$ of $0 \Omega$ show the series resistance $\left(R_{s}\right)$ and the sum of the series resistance and the parallel resistance $\left(R_{s}+R_{p}\right)$, respectively.

Figures $7(\mathrm{a})$ and $7(\mathrm{~b})$ show the parallel resistance $\left(R_{p}\right)$ and the series resistance $\left(R_{s}\right)$ of fuel cells assembled with the bare SS bipolar plates or those coated with the CNT/PTFE composite film at various CNT concentrations. The bare SS bipolar plate showed 35 and $37 \mathrm{~m} \Omega$ in the parallel and the series resistance, respectively. The parallel resistance slightly increased with the film coating on the SS bipolar plate. When the CNT/PTFE composite film was coated at $5 \mathrm{wt} . \%$, the series resistance increased from 37 to $86 \mathrm{~m} \Omega$. On the other hand, the coating of the CNT/PTFE composite film at $25 \mathrm{wt} . \%$ decreased the series resistance below $20 \mathrm{~m} \Omega$, which is lower than that of the bare SS bipolar plates.

Figure 7 (c) shows the maximum output power of the fuel cells assembled with various types of bipolar plates. The fuel cell assembled with the bare SS bipolar plates showed the $106 \mathrm{~mW} / \mathrm{cm}^{2}$ in the maximum power. The coating of the CNT/PTFE composite film at 5 wt.\% decreased the output power to $5 \mathrm{~mW} / \mathrm{cm}^{2}$. The coating of the CNT/PTFE composite film above $25 \mathrm{wt}$.\% increased the output power up to $167 \mathrm{~mW} / \mathrm{cm}^{2}$, which is 1.6 times higher than that of the bare SS bipolar plates.

The CNT/PTFE composite film at the CNT concentration of $5 \mathrm{wt} . \%$ has low electrical conductivity of $0.1 \mathrm{~S} / \mathrm{cm}$. Therefore, the coating of this composite film on the bipolar plate decreases the output power of the fuel cell. The coating of the CNT/PTFE composite film above $25 \mathrm{wt}$.\% decreases the contact resistance between the bipolar plate and the carbon paper, because these films have high electrical conductivity above $2 \mathrm{~S} / \mathrm{cm}$. The decrease in the contact resistance decreases the series resistance of the fuel cell and increases the output power. Moreover, the higher CNT concentration in the film causes higher output power of the fuel cell.

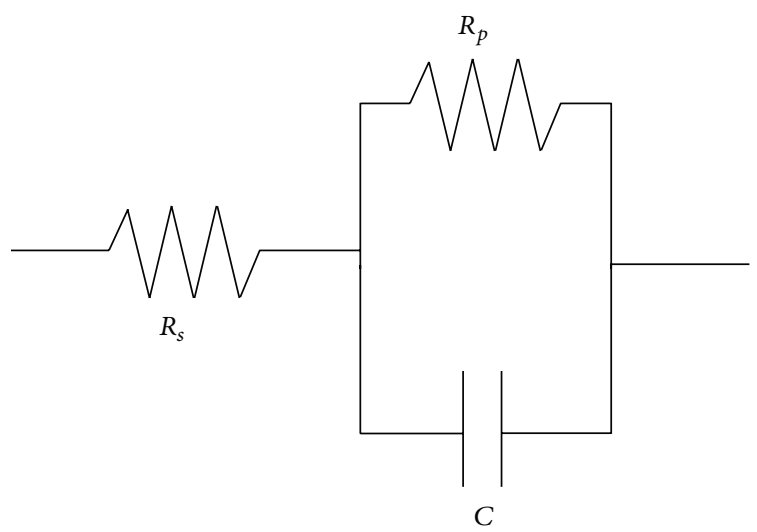

FIGURE 6: The equivalent circuit for a fuel cell, which was used for estimating the series resistance $\left(R_{s}\right)$ and parallel resistance $\left(R_{p}\right)$.

Figure 8 shows polarization curve for the bare and the $\mathrm{CNT} / \mathrm{PTFE}$ composite film coated SS plates. The bare SS plate showed the corrosion potential of $-326 \mathrm{mV}$ versus $\mathrm{Ag} / \mathrm{AgCl}$. The strong peak of active-passive transition appeared at $-230 \mathrm{mV}$ versus $\mathrm{Ag} / \mathrm{AgCl}$. On the other hand, the SS plates coated with the CNT/PTFE composite film showed the corrosion potential of $+180 \mathrm{mV}$ versus $\mathrm{Ag} / \mathrm{AgCl}$. No peak originated from the active-passive transition was observed for the film coated stainless steel. The bare SS plate was $5 \times$ $10^{-5} \mathrm{~A} / \mathrm{cm}^{2}$ in the passive current at the potential of $600 \mathrm{mV}$ versus $\mathrm{Ag} / \mathrm{AgCl}$. Although the passive current increased from $5.5 \times 10^{-6}$ to $1.6 \times 10^{-5} \mathrm{~A} / \mathrm{cm}^{2}$ with an increase in the CNT concentration, the SS plates coated with the CNT/PTFE composite film were lower than the bare SS plate in the current. The shift of the corrosion potential and the disappearance of the peak for the active-passive transition indicate that the SS plates are completely coated with the CNT/PTFE composite film without formation of pin holes. Moreover, the decrease in the passive current suggests that the CNT/PTFE composite film protects the SS bipolar plates from the surface corrosion during the operation of the fuel cell.

The above results indicate that the coating of CNT/PTFE composite film on the bipolar plate increases the output power and the lifetime of the fuel cell. The coating of amorphous carbon film by the chemical vapor deposition (CVD) method has also been reported to increase the output power of the fuel cell by 1.4 times, because the contact resistance between the bipolar plate surface and the MEA is decreased $[16,17]$. Moreover, the electrochemical measurement shows that the coating of carbon film enhances the corrosion resistance of the stainless steel $[18,19]$. On the other hand, the deposition of CNT directly on stainless steel by the catalytic deposition of $\mathrm{C}_{2} \mathrm{H}_{2}$ has also been reported to decrease the contact resistance to carbon paper [20]. The above previous reports commonly use vacuum process to deposit the carbon film or the CNT on the bipolar plate. The coating of the CNT/PTFE composite film, which was carried out in this study, has an advantage that it of is lower cost than that of the amorphous carbon film because this coating does not require vacuum process. 


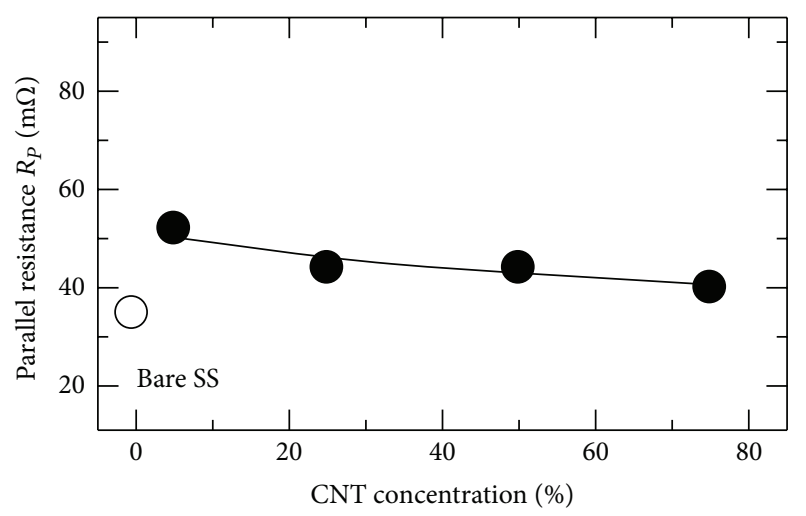

(a)

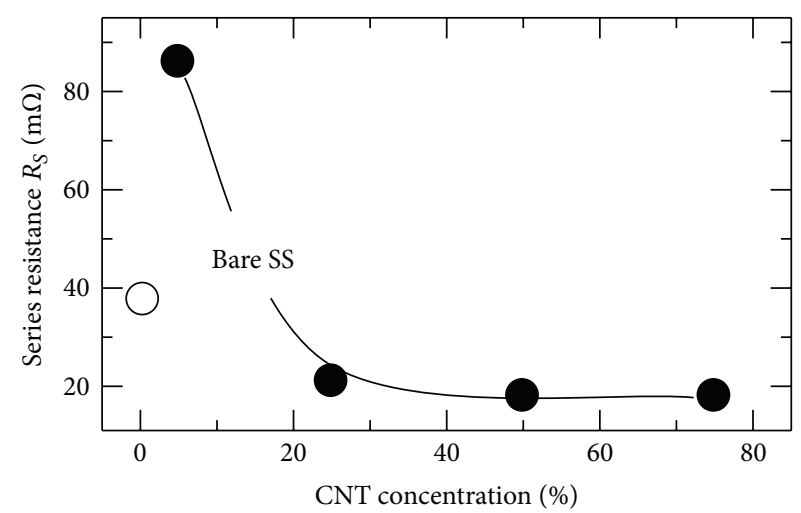

(b)

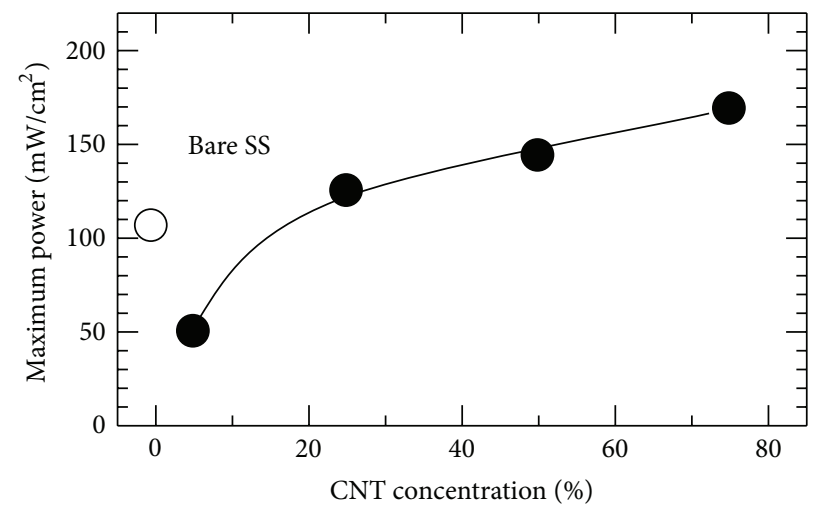

(c)

FiguRE 7: (a) The parallel resistance $\left(R_{p}\right)$, (b) the series resistance $\left(R_{s}\right)$, and (c) the maximum power of fuel cells assembled with bare stainless steel (SS) bipolar plates and those coated with the CNT/PTFE composite film at various CNT concentrations.

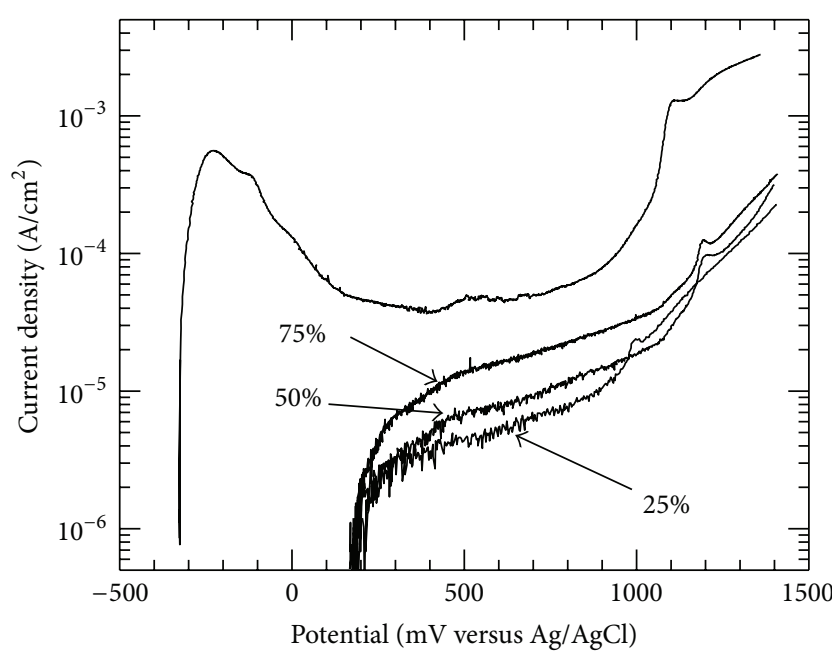

FIgURE 8: Polarization curves for the bare stainless steel (SS) plate and the SS plates coated with CNT/PTFE composite film at various CNT concentrations.

\section{Summary}

The CNT/PTFE composite film with high electrical conductivity in the order of $5-13 \mathrm{~S} / \mathrm{cm}$ was coated on the stainless steel (SS) bipolar plates. This conductive film coating reduced contact resistance between its surface and the MEA. Therefore, the fuel cell assembled with the SS bipolar plate coated with this film showed lower series resistance by half and higher output power by 1.6 times than that of the bare (no film coating) SS bipolar plates. This CNT/PTFE composite film coating improves the efficiency of fuel cell in the electric power generation. Moreover, this film protects the SS bipolar plates from the surface corrosion during the operation of the fuel cell.

\section{Acknowledgments}

The authors would like to thank Mr. K. Miura of Ohashi Kasuga Tsusho Inc. for technical support of producing CNT dispersion fluid. This work was supported by JSPS KAKENHI 23560803, JST A-STEP, and Suzuki Foundation.

\section{References}

[1] T. Tong, Y. Zhao, L. Delzeit, A. Kashani, M. Meyyappan, and A. Majumdar, "Dense vertically aligned multiwalled carbon nanotube arrays as thermal interface materials," IEEE Transactions on Components and Packaging Technologies, vol. 30, no. 1, pp. 92-100, 2007.

[2] M. Nihei, A. Kawabata, D. Kondo, M. Horibe, S. Sato, and Y. Awano, "Electrical properties of carbon nanotube bundles for 
future via interconnects," Japanese Journal of Applied Physics, vol. 44, no. 4, pp. 1626-1628, 2005.

[3] E. J. Garcia, B. L. Wardle, and A. John Hart, "Joining prepreg composite interfaces with aligned carbon nanotubes," Composites A, vol. 39, no. 6, pp. 1065-1070, 2008.

[4] W. X. Chen, F. Li, G. Han et al., "Tribological behavior of carbon-nanotube-filled PTFE composites," Tribology Letters, vol. 15, pp. 275-278, 2003.

[5] D. L. Burris, B. Boesl, G. R. Bourne, and W. G. Sawyer, "Polymeric nanocomposites for tribological applications," Macromolecular Materials and Engineering, vol. 292, no. 4, pp. 387-402, 2007.

[6] N. Rungraeng, Y.-C. Cho, S. H. Yoon, and S. Jun, "Carbon nanotube-polytetrafluoroethylene nanocomposite coating for milk fouling reduction in plate heat exchanger," Journal of Food Engineering, vol. 111, no. 2, pp. 218-224, 2012.

[7] A. Pozio, R. F. Silva, M. De Francesco, and L. Giorgi, "Nafion degradation in PEFCs from end plate iron contamination," Electrochimica Acta, vol. 48, no. 11, pp. 1543-1549, 2003.

[8] H. Tawfik, Y. Hung, and D. Mahajan, "Metal bipolar plates for PEM fuel cell-a review," Journal of Power Sources, vol. 163, no. 2, pp. 755-767, 2007.

[9] Y. Show and H. Itabashi, "Electrically conductive material made from CNT and PTFE," Diamond and Related Materials, vol. 17, no. 4-5, pp. 602-605, 2008.

[10] Y. Show and K. Takahashi, "Stainless steel bipolar plate coated with carbon nanotube (CNT)/polytetrafluoroethylene (PTFE) composite film for proton exchange membrane fuel cell (PEMFC)," Journal of Power Sources, vol. 190, no. 2, pp. 322-325, 2009.

[11] T. Takahashi, K. Tunoda, H. Yajima, and T. Ishii, "Dispersion and purification of single-wall carbon nanotubes using carboxymethylcellulose," Japanese Journal of Applied Physics, vol. 43, no. 6A, p. 3636, 2004.

[12] N. Minami, Y. Kim, K. Miyashita, S. Kazaoui, and B. Nalini, "Cellulose derivatives as excellent dispersants for single-wall carbon nanotubes as demonstrated by absorption and photoluminescence spectroscopy," Applied Physics Letters, vol. 88, p. 93123, 2006.

[13] M. N. Nadagouda and R. S. Varma, "Noble metal decoration and alignment of carbon nanotubes in carboxymethyl cellulose," Macromolecular Rapid Communications, vol. 29, no. 2, pp. 155159, 2008.

[14] S. Kirkpatrick, "Percolation and conduction," Reviews of Modern Physics, vol. 45, pp. 574-588, 1973.

[15] J. P. Owejan, T. A. Trabold, D. L. Jacobson, M. Arif, and S. G. Kandlikar, "Effects of flow field and diffusion layer properties on water accumulation in a PEM fuel cell," International Journal of Hydrogen Energy, vol. 32, no. 17, pp. 4489-4502, 2007.

[16] Y. Show, "Electrically conductive amorphous carbon coating on metal bipolar plates for PEFC," Surface and Coatings Technology, vol. 202, pp. 1252-1255, 2007.

[17] Y. Show, M. Miki, and T. Nakamura, "Increased in output power from fuel cell used metal bipolar plate coated with a-C film," Diamond and Related Materials, vol. 16, no. 4-7, pp. 1159-1161, 2007.

[18] T. Fukutsuka, T. Yamaguchi, S.-I. Miyano, Y. Matsuo, Y. Sugie, and Z. Ogumi, "Carbon-coated stainless steel as PEFC bipolar plate material," Journal of Power Sources, vol. 174, no. 1, pp. 199205, 2007.
[19] K. Feng, X. Cai, H. Sun, Z. Li, and P. K. Chu, "Carbon coated stainless steel bipolar plates in polymer electrolyte membrane fuel cells," Diamond and Related Materials, vol. 19, no. 11, pp. 1354-1361, 2010.

[20] Y.-B. Lee, C.-H. Lee, and D.-S. Lim, “The electrical and corrosion properties of carbon nanotube coated 304 stainless steel/ polymer composite as PEM fuel cell bipolar plates," International Journal of Hydrogen Energy, vol. 34, no. 24, pp. 9781-9787, 2009. 

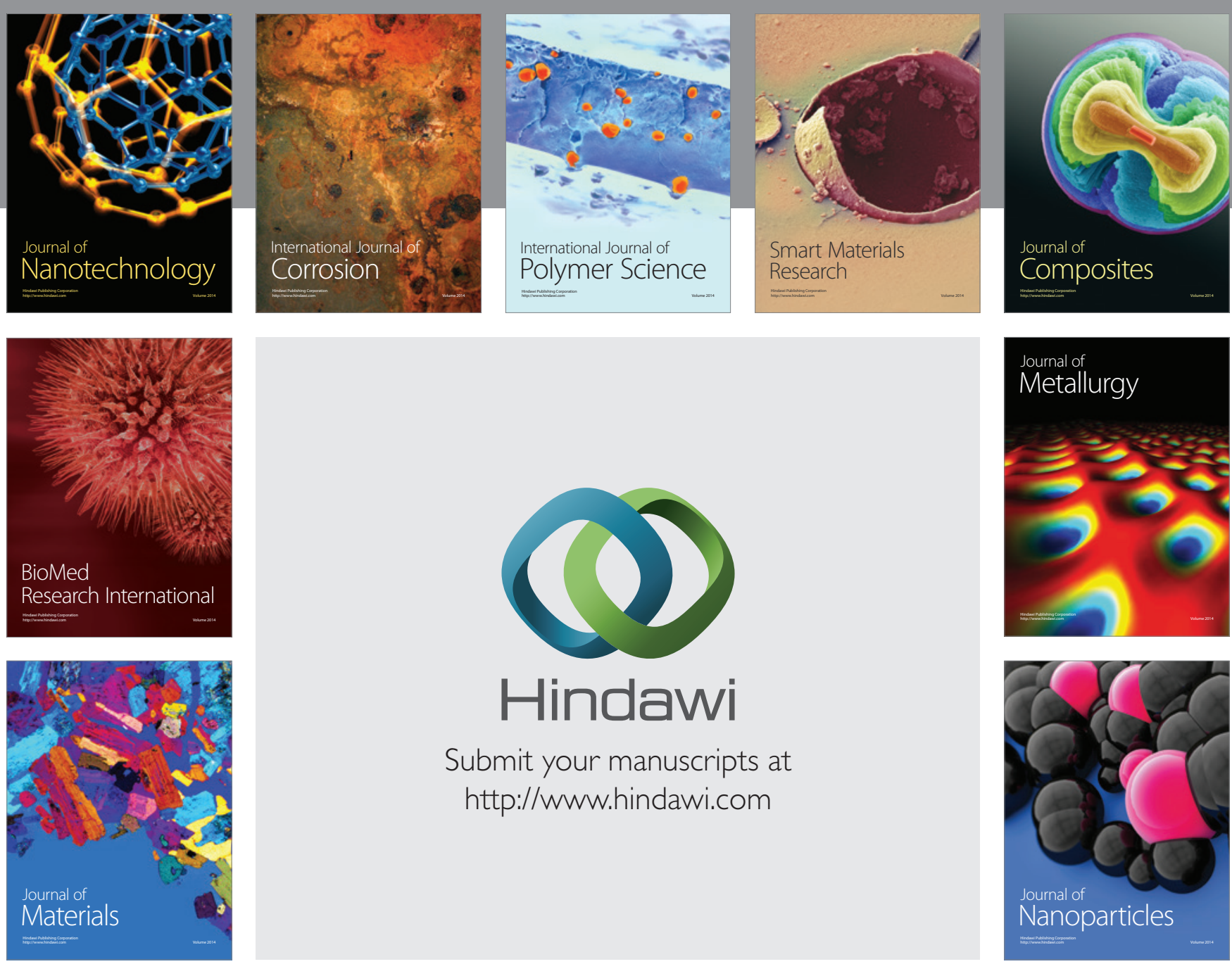

Submit your manuscripts at http://www.hindawi.com
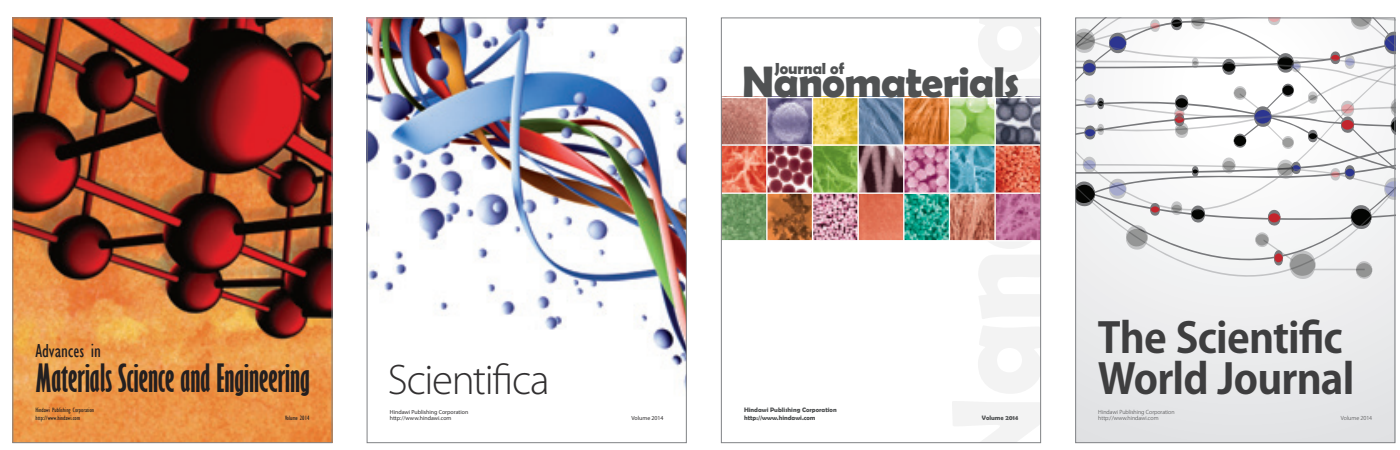

\section{The Scientific World Journal}
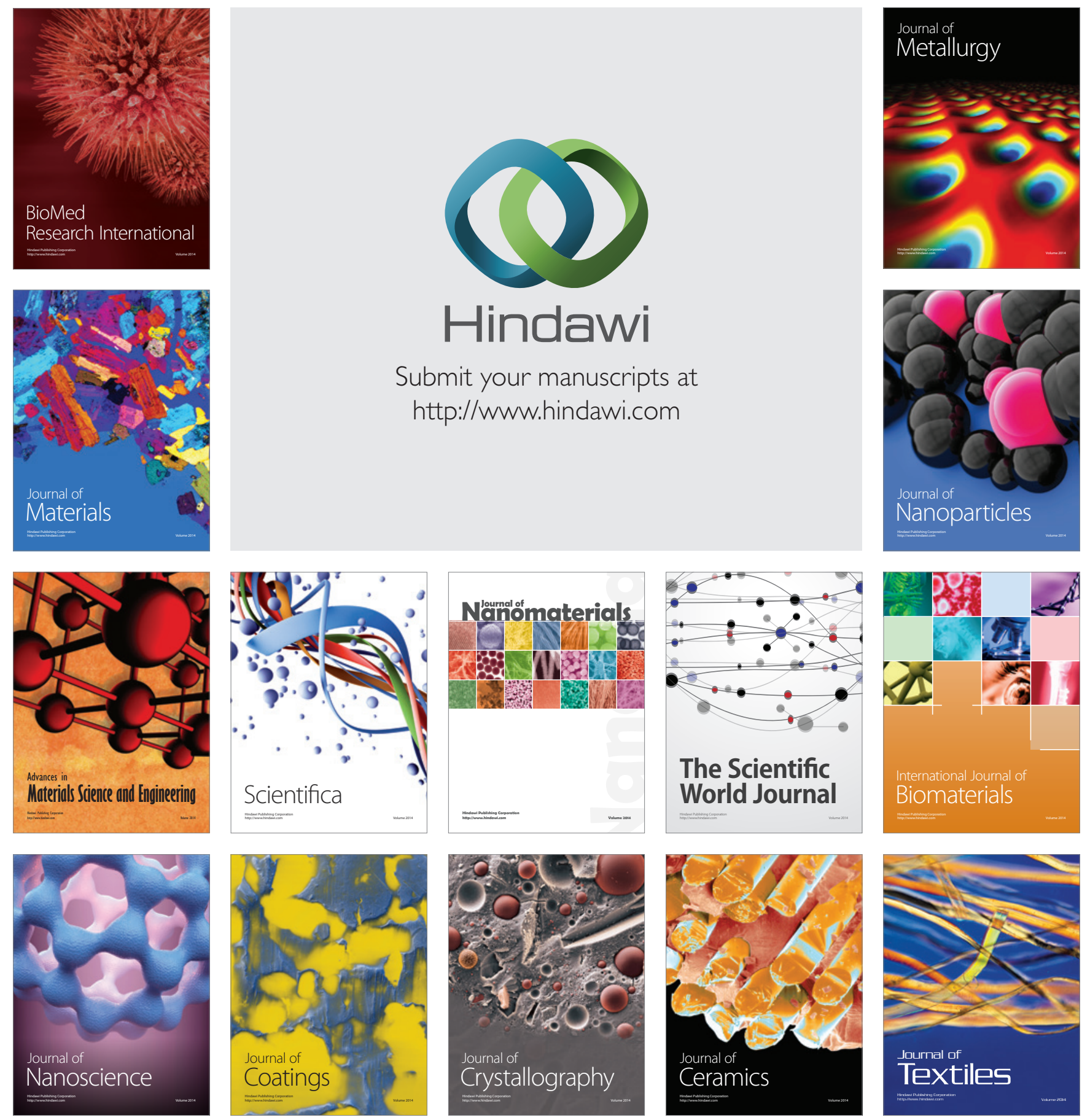